\title{
PATOLOGIZAÇÃO DA TRANSEXUALIDADE: UMA LEI- TURA CRÍTICA DAS TRANSFORMAÇÕES OCORRIDAS NAS TRÊS ÚLTIMAS VERSÕES DO DSM
}

\section{Roberto de Oliveira Preu' \\ Carolina Franco Brito ${ }^{2}$}

Resumo: $O$ presente artigo possui como objetivo principal compreender se a categoria psiquiátrica de Disforia de Gênero, criada para definir pessoas transexuais, funciona ainda como vetor de patologização da homossexualidade. Esta pesquisa foi realizada e dividida em duas partes. No primeiro momento foi feita uma análise crítica das categorias diagnósticas de transexualidade nas últimas três edições do DSM. No segundo, foi estabelecida uma relação entre o diagnóstico de Disforia de Gênero com a homossexualidade. Faz-se uso de uma metodologia de análise bibliográfica de artigos sobre o tema referido e do instrumento psiquiátrico em questão, o DSM.

Palavras chave: homossexualidade; transexualidade; DSM.

Abstract: The main objective of this article is to understand if the psychiatric category of Gender Dysphoria, created to define transsexual people, still acts as a pathologizing vector for homosexuality. This research was produced and divided into two sections. In the first one, a critical analysis on the diagnostic categories of transsexuality in DSM's three last editions will be performed. In the second part, the relationship between diagnosis of Gender Dysphoria and homosexuality will be established. The methodology used includes bibliographic analysis of articles on the subject referred and of the psychiatric instrument in question, the DSM.

Keywords: homosexuality; transsexuality; DSM.

\section{Introdução}

Nas diferentes ciências se faz presente um pensamento hegemônico acerca das noções de sexo e gênero. Estas questões começaram a ganhar maior visibilidade com as discussões sobre os assuntos concernentes à comunidade LGBT (lésbicas, gays, bissexuais, travestis e transexuais), a qual tem estado cada vez mais em evidência, estando mais presente na pauta das discussões - ainda que

\footnotetext{
1 Doutor em Psicologia pela Universidade de São Paulo. Professor do Departamento de Psicologia da Universidade Federal Fluminense. E-mail: robbypreu@gmail.com 
por motivações diversas - tanto da comunidade científica, quanto do restante da população.

Os estudos de gênero são herdeiros de uma longa produção no campo das ciências humanas (entre elas, antropologia, sociologia, psicologia, filosofia e psicanálise) os quais remetem, em geral, à forma como essas disciplinas se estabeleceram, desde sua emergência, no século XIX, a partir da distinção entre natureza e cultura. A crítica proposta por Judith Butler (2014) a esse viés epistemológico é base para a construção deste trabalho, partindo da perspectiva que considera a ciência e seus objetos resultados de uma produção histórica. Assim, ao se tratar da distinção comumente feita entre sexo e gênero, usar-se-á sempre o sentido de considerar a produção histórica desses termos, como bem ilustra o trabalho do Thomas Laqueur (2001) ao evidenciar que o dimorfismo ${ }^{3}$ da sexualidade tem sua emergência com o surgimento das ciências biológicas dos séculos XVIII e XIX. Nesse sentido, objetiva esse trabalho uma revelação do aspecto naturalizante do Manual Diagnóstico e Estatístico de Transtornos Mentais (DSM) e também uma demonstração de que mesmo em suas versões mais contemporâneas existem ainda resquícios desse preconceito naturalizante, especialmente no que tange à questão trans.

$\bigcirc$ conceito de gênero aparece historicamente para atenuar o aspecto natural conferido à sexualidade, mantendo a dicotomia natureza/cultura e atribuindo diferenças comportamentais a variações no quesito cultural. Scott (1995, p. 72) afirma que

O termo "gênero" parece ter feito sua aparição inicial entre as feministas americanas, que queriam enfatizar o caráter fundamentalmente social das distinções baseadas no sexo. A palavra indicava uma rejeição do determinismo biológico implícito no uso de termos como "sexo" ou "diferença sexual".

○ sexo é, portanto, entendido como um elemento da natureza, em função dessa dicotomia criada no século XVIII. É localizado no corpo, nos órgãos sexuais e reprodutores. A partir de uma "identificação" das caracteristicas físicas feita pela medicina, os individuos são diferenciados em corpos-homens e corpos-mulheres (BENTO, 2014). Após essa nomeação dos corpos, são esperados certos comportamentos desses indivíduos que serão socializados de maneiras distintas. Com base no sexo biológico são definidos os papéis de gênero, expressos, por exemplo, em meninas brincando de bonecas e meninos de carrinhos, como se uma coisa fosse resultante óbvia de outra (BUTLER, 2009). Contudo, algumas vivências que contrariam essa linearidade, postulada forçosamente como natural,

3 Segundo Ayouch (2015, p. 28), "foi só no século XVIII que começou a aparecer o modelo do dimorfismo que coloca a ênfase sobre as diferenças anatômicas, opõe radicalmente os corpos feminino e masculino e faz proceder a sexualidade e as sexuações da biologia dos corpos". 
começaram a se tornar objeto de estudo de diferentes áreas do saber, como a psiquiatria, a sexologia, a sociologia e a psicologia. Uma definição diferente de gênero se estabeleceu para dar conta da compreensão das existências consideradas desviantes e patológicas - até os dias atuais - como a transexualidade. $\bigcirc$ gênero foi concebido de maneira dicotômica ao sexo: enquanto este era definido pela natureza, o gênero seria fruto de uma construção social, ou seja, passa a ser entendido como a identidade que o sujeito constitui na sociedade, podendo estar ou não de acordo com seu sexo e ainda extrapolar a binaridade homem/mulher (ARÁN, 2006).

As diferentes vivências que compõem as siglas LGBT representam uma minoria que ainda é entendida como desviante, pois não obedece a norma socialmente estabelecida e naturalizada: espera-se que os sujeitos apresentem uma linearidade entre sexo, gênero, desejo e práticas sexuais (ARÁN, 2006). Essa linearidade pode ser entendida a partir do conceito da heterossexualidade compulsória, trazido à cena pelos estudos de Judith Butler e inaugurado a partir da década de 1990. Segundo Butler (2014), esse conceito de heterossexualidade compulsória surge nos estudos de Adrienne Rich e serve

Para caracterizar o modelo discursivo/epistemológico hegemônico da inteligibilidade do gênero, o qual presume que, para os corpos serem coerentes e fazerem sentido (masculino expressa macho, feminino expressa fêmea), é necessário haver um sexo estável, expresso por um gênero estável, que é definido oposicional e hierarquicamente por meio da prática compulsória da heterossexualidade. (BUTLER, 2014, p. 216).

Em uma sociedade que funciona sob a lógica da heterossexualidade compulsória, qualquer fissura no contínuo sexo, gênero, desejo e práticas sexuais, é frequentemente colocada em questão e analisada como anormalidade (BENTO, 2014). Neste trabalho, tematizar-se-á a homofobia presente em diversas instâncias sociais, inclusive em alguns discursos científicos e acadêmicos. Essa homofobia também se apresenta, atualmente, nos discursos que visam à patologização da vivência trans, entendendo que o diagnóstico de "transexualismo" é ainda, em certa medida, um diagnóstico de homossexualidade. Somada à transfobia, sofrida diariamente por diversos sujeitos, está também a homofobia, que apesar de dizer respeito à vivências diferentes, são sistematicamente associadas. Sublinha-se aqui que, apesar de considerar a homofobia um fenômeno que atinge toda a população LGBT, no presente trabalho o foco é mais diretamente o estudo das vivências de pessoas trans.

Algumas existências ainda estão diretamente submetidas ao discurso patológico e são consideradas doenças - já o foram no passado e são constantemente ameaçadas a voltar para esse discurso no presente, constatação muito claramen- 
te exemplificada, por exemplo, tomando como referência um debate ocorrido no final do ano de 2017, no Brasil: a homossexualidade e a homofobia compuseram de forma muito polêmica a pauta do dia na grande imprensa nacional depois de uma decisão provisória de primeira instância de um juiz do Distrito Federal (DF) permitindo aos psicólogos brasileiros a oferta de atendimento psicológico de reorientação sexual. Durante a audiência, a Resolução 001/1999 do ConseIho Federal de Psicologia (CFP), órgão estabelecedor das normas de atuação desses profissionais sobre as questões de orientação sexual - o qual reconhece a homossexualidade como um dos modos de expressão sexual, não constituindo, portanto, uma patologia - foi interpretada pelo juiz como um ato de censura. Foi conformado, então, que a resolução se mantivesse, porém, autorizou-se a oferta desse tipo de "tratamento" para as pessoas que assim desejassem (IOTTI, 2017). Tal decisão representou um retrocesso social, na medida em que, mesmo que de maneira implícita, passou a entender a homossexualidade como doença, localizando as causas do sofrimento não na sociedade homofóbica, mas sim no próprio sujeito. Desde 1990 a Organização Mundial da Saúde (OMS) reconhece que a homossexualidade não constitui uma patologia e diversos estudos e relatos de experiência comprovam que as terapias de reversão sexual não são eficazes, provocando o inverso do esperado: mais sofrimento psíquico àqueles que são submetidos a elas. O CFP se posicionou de maneira contrária a essa decisão do juiz, afirmando que a oferta desse tipo de atendimento fere os direitos humanos e que a resolução posta em questão pelo júri não seria aceita como censura à liberdade profissional dos psicólogos e nem mesmo às pesquisas na área de sexualidade (IOTTI, 2017).

Apesar do fato da homossexualidade ter deixado de compor as listas de doenças há anos - em 1980 foi retirada do DSM e em 1990 da Classificação Estatística Internacional de Doenças e Problemas Relacionados com a Saúde (CID) - as diferentes ciências ainda defendem termos e noções intrigantes, como a categoria Disforia de Gênero que funciona, de certo modo, como uma extensão do diagnóstico de homossexualidade (BUTLER, 2009). Uma questão parece se impor, então: essa categoria diagnóstica, criada para definir pessoas transexuais, funciona como vetor de patologização da homossexualidade? É necessário avaliar o quanto a normatização dos corpos opera de diferentes maneiras, entre elas, através da psiquiatrização das "vivências perversas", ou seja, das existências desviantes da norma socialmente estabelecida.

Assim dito, reafirma-se nesse ponto o desenvolvimento deste artigo posto em dois tópicos: no primeiro, uma breve apresentação do processo de patologização da transexualidade pela psiquiatria, além de uma análise de um dos instrumentos dessa área do saber: o DSM; no segundo, o estabelecimento de uma relação entre a categoria diagnóstica de Disforia de Gênero e a homossexualidade. 


\title{
Análise das categorias diagnósticas de transexualidade das edições III, IV e V do DSM
}

O Manual Diagnóstico e Estatístico de Transtornos Mentais (DSM) é um instrumento psiquiátrico formulado pela Associação Americana de Psiquiatria (APA) e consiste em uma lista de transtornos mentais apresentados a partir de sintomas e identificáveis através de códigos. Buscando alcançar uma confiabilidade diagnóstica, esse é um manual descritivo e ateórico, sem grandes preocupações com a etiologia dos transtornos definidos em suas páginas. Apesar de esse instrumento guiar a prática da maioria dos psiquiatras, é também utilizado por profissionais de outras áreas do saber, apresentando e estabelecendo uma norma e seus desvios. Uma questão parece se impor quando tratamos desse assunto: seria possivel dizer que o DSM atua como um mecanismo de poder e é responsável pela normatização dos corpos e vivências a partir da patologização e psiquiatrização do prazer perverso?

A transexualidade é transformada em categoria psiquiátrica na terceira edição do manual, publicada em fevereiro de 1980, sob o nome de Transtorno de Identidade de Gênero (TIG). Segundo a APA, se trata de uma perturbação rara e consiste na

\begin{abstract}
Incongruência entre sexo anatômico e identidade de gênero. A identidade de gênero é o senso de saber a que sexo pertence, ou seja, a consciência de que "eu sou um homem", ou "eu sou uma mulher". A identidade de gênero é a experiência privada do papel de gênero e o papel de gênero é a expressão pública da identidade de gênero. $O$ papel de gênero pode ser definido como tudo o que se diz e faz, incluindo a excitação sexual, para indicar aos outros ou a si o grau de masculino ou feminino. (DSM-III, 1980, p. 261, tradução nossa) ${ }^{4}$.
\end{abstract}

É estabelecida aqui a dicotomia entre sexo, considerado biológico, e gênero, entendido como uma expressão social do sexo. Para o diagnóstico é preciso que se verifique um sentimento de inadequação do sujeito quanto à biologia do seu corpo, o que deve acontecer ao longo de pelo menos dois anos, além do consequente desejo de modificação corporal para viver de acordo com sua realidade psíquica. Essa incongruência se expressaria através do comportamento do sujeito transexual que estaria conforme os padrões sociais de masculinidade ou feminilidade oposto ao seu sexo. Sendo assim, meninas com TIG gostariam mais de criar vínculos com grupos de meninos e apresentariam "grande interes-

\footnotetext{
$4 \quad$ DSM-III. Texto em língua original: "Incongruence between anatomic sex and gender identity. Gender identity is the sense of knowing to which sex one belongs, that is, the awareness that 'I am a male/' or 'I am a female.' Gender identity is the private experience of gender role, and gender role is the public expression of gender identity. Gender role can be defined as everything that one says and does, including sexual arousal, to indicate to others or to the self the degree to which one is male or female".
} 
se em esportes e jogos rudes e agressivos e uma falta de interesse em brincar com bonecas ou de 'casinha' (a menos que brinque no papel de pai ou de outro papel masculino)" (DSM-III, 1980, p. 264)5 (Tradução nossa), enquanto que os meninos prefeririam usar "roupas de meninas ou mulheres" (DSM-III, 1980, p. 264) ${ }^{6}$ (Tradução nossa), e brincar de boneca.

Além de tentar criar uma relação entre a transexualidade e os diferentes tipos de sexualidade, a saber, homossexualidade, heterossexualidade e assexualidade, a APA, nessa versão do manual, ainda associa essa vivência a acontecimentos da tenra infância. Ao falar sobre os fatores predisponentes, afirma que

A proximidade física e emocional extrema, excessiva e prolongada entre o bebê e a mãe e uma ausência relativa do pai durante os primeiros anos pode contribuir para o desenvolvimento desse distúrbio no homem. As fêmeas que mais tarde desenvolveram esse transtorno têm mães que, aparentemente, não estavam disponiveis para elas em uma idade muito precoce, psicologicamente ou fisicamente, devido à doença ou abandono; A menina parece fazer uma identificação compensatória com o pai, o que leva à adoção de uma identidade de gênero masculina. (DSM-III, 1980, p. 265, tradução nossa $\left.{ }^{7}\right)^{8}$.

Essa versão do manual foi substituída em 1994 pela publicação do DSM-IV. Na nova edição permanece a categoria diagnóstica de TIG, apesar de sua modificação e ampliação. A partir de então, foram estabelecidos quatro critérios que precisariam ser cumpridos pelos sujeitos para serem diagnosticados com esse "transtorno". O primeiro deles diz que "deve haver evidências de uma forte e persistente identificação com o gênero oposto, que consiste no desejo de ser, ou a insistência do indivíduo de que ele é do sexo oposto" (DSM-IV, 2002, p. 547). O segundo cria a condição para essa identificação: "não deve refletir mero desejo de quaisquer vantagens culturais percebidas por ser do outro sexo" (DSM-IV, 2002, p. 547). O terceiro critério aponta para as condições biológicas do sujeito: "o diagnóstico não é feito se o indivíduo tem uma condição

5 DSM-III. Texto em língua original: "An avid interest in sports and rough-and-tumble play, and a lack of interest in playing with dolls or playing 'house' (unless playing the father or another male role)".

6 DSM-III. Texto em língua original: "dressing in girls' or women's clothes".

7 Segundo Dunker e Kyrillos Neto (2011, p. 2-3), "há vários trabalhos que descrevem, particularmente a partir do DSM III (1980-1987), o processo gradual de retirada de categorias e signos clínicos de extração psicanalítica e sua substituição por entidades 'propriamente psiquiátricas"'. A partir dessa virada as categorias do DSM se tornam mais descritivas e ateóricas, transformando-se em mera descrição de comportamentos observados e tirando de cena, por assim dizer, todo o debate que é travado nos bastidores entre diferentes profissionais das ciências psi. Esta citação traz resquícios dessa influência psicanalítica sob o DSM nesse momento.

8 DSM-III. Texto em língua original: "Extreme, excessive, and prolonged physical and emotional closeness between the infant and the mother and a relative absence of the father during the earliest years may contribute to the development of this disorder in the male. Females who later develop this disorder have mothers who were apparently unavailable to them at a very early age, either psychologically or physically, because of illness or abandonment; the girl seems to make a compensatory identification with the father, which leads to the adoption of a male gender identity". 
intersexual física concomitante" (DSM-IV, 2002, p. 547), em uma tentativa de diferenciar os intersexuais dos transexuais. E, por fim, o quarto critério diz que é preciso "haver evidências de sofrimento clinicamente significativo ou prejuizo no funcionamento social ou ocupacional ou em outras áreas importantes da vida do indivíduo" (DSM-IV, 2002, p. 548).

Essa definição inicial, feita nas características diagnósticas, já apresenta alguns pontos passiveis de críticas, o que foi feito, dentre tantos pesquisadores, por Judith Butler, questionando de início a noção de identificação que o manual utilizou, supondo que é possivel saber e ter acesso a elas somente com base nos comportamentos do indivíduo. Butler (2009, p. 114) diz que, na verdade, muitas vezes as identificações "podem persistir como aspectos de fantasias ocultas, ou partes de sonhos, ou estruturas incipientes de comportamento". Além disso, ainda no primeiro critério, ao afirmar sobre o que implica essa identificação, é utilizado o termo "ou" permitindo o entendimento de que é possivel um indivíduo ter desejo de ser do outro sexo sem insistir nisso obrigatoriamente. Isso significa que é possivel um diagnóstico de TIG mesmo quando o indivíduo não diz, em nenhum momento, que possui o desejo de ser de outro sexo. A insistência seria apenas mais um dos pontos que ajudaria a fechar o diagnóstico, mas poderia também não estar presente. Fica claro, no decorrer desse tópico do manual, que as descrições que poderiam determinar esse desejo - mesmo que não revelado em palavras - são feitas com base em observações reunidas e resumidas acerca dos comportamentos estereotipados dos gêneros dos sujeitos, como por exemplo, um menino brincando de Barbie ${ }^{9}$.

O segundo critério fala do necessário desinteresse em conseguir vantagens culturais do sexo ao qual se deseja pertencer. Mas será isso possivel? Butler (2009, p. 115) questiona e afirma:

Se o sexo é experienciado por nós em uma matriz cultural de sentidos, se ele recebe sua significação e sentido com referência a um amplo mundo social, então podemos separar a experiência do "sexo" de seus significados sociais, incluindo o modo pelo qual o poder funciona através desses significados? "Sexo" é um termo que se aplica ao conjunto da população, de modo que é difícil se referir ao meu "sexo" tal como se ele fosse radicalmente singular.

Logo, seria inviável pensar e compreender o sexo de uma maneira singular e à parte da matriz cultural na qual estamos inseridos e das suas relações de 9 A referência à Barbie é literal: "bonecas estereotipicamente femininas, tais como a Barbie [...]" (DSM-IV, 2002, p. 548).

10 Essa mesma caracterização aparece também no DSM-V. Segundo Freire (2015, p. 122), "ao elencar determinadas características como critérios diagnósticos da disforia de gênero em crianças, os médicos não identificam uma espécie de transtorno mental, mas sim asseguram um 'correto' desenvolvimento do gênero ao produzir meninos-masculinos e meninas-femininas, ditando como, com o que e com quem as crianças devem conviver e brincar". 
poder. Matriz esta em que estão presentes vantagens de diversos tipos associadas aos sexos e seus papéis.

Com relação ao quarto e último critério, Butler (2009) diz que é preciso questionar o porque do sofrimento intenso e do comprometimento social. Segundo o manual, isso ocorre porque a pessoa está vivenciando o gênero errado, e, sendo assim, ao se adequar ao gênero que ela se identifica, ou melhor, a uma norma de gênero, produziria mudanças, reduzindo os sentimentos de sofrimento e inadequação (DSM-IV, 2002). Localiza-se as causas no indivíduo, desresponsabilizando o social e as normas de gênero, pressupostas como imutáveis e fixas e que, sendo assim, acabam por gerar sofrimento em muitas pessoas que são impossibilitadas de viver da maneira que querem e sentem.

Em 2013 foi publicada a quinta versão do DSM, em vigor atualmente. Nela, a transexualidade continua sendo patologizada pela APA, entretanto, algumas transformações foram feitas na categoria, a começar pelo próprio nome, que deixou de ser Transtorno de Identidade de Gênero e se tornou Disforia de Gênero. Segundo o próprio manual, "o termo atual é mais descritivo do que o termo anterior transtorno de identidade de gênero, do DSM-IV, e foca a disforia como um problema clínico, e não como identidade por si própria" (DSM-V, 2014, p. 452). O termo disforia, segundo o dicionário Michaelis (2018), se refere a "instabilidade do humor acompanhada de mal-estar, inquietude e frequentemente reações coléricas". Ele é utilizado no DSM-V para descrever sintomas presentes em diferentes transtornos mentais, sendo alguns deles Transtorno Bipolar e Transtornos Relacionados, Transtornos Depressivos, Transtorno Dismórfico Corporal, Transtornos Alimentares e Transtorno da Personalidade Boderline. Contudo, para a APA, quando a disforia está relacionada ao gênero, ela diz de um "[...] descontentamento afetivo/cognitivo de um indivíduo com o gênero designado, embora seja definida mais especificamente quando utilizada como categoria diagnóstica" (DSM-V, 2014, p. 451).

O início da categoria diagnóstica se dá com uma espécie de introdução onde são esclarecidos alguns termos usados, como: sexo, gênero, designação de gênero, atípicas com o gênero ou não conforme o gênero, redesignação de gênero, identidade de gênero, Disforia de Gênero, transgênero e transexual. Contudo, na base de todas essas noções, que possibilitam certa definição e entendimento do que é a Disforia de Gênero, pela APA, estão as dicotomias: sexo e gênero, natureza e cultura. Essa base vem como herança das versões anteriores do DSM, das ciências e de uma sociedade que concebe a normalidade e a saúde com base na "suposta coerência entre o sexo biológico e o gênero cultural" (BENTO e PELÚClO, 2012, p. 570). Segundo o DSM-V (2014), quando nascemos nos é designado um gênero a partir dos "indicadores biológicos clássicos" que determinam se somos homens ou mulheres. Isso quer dizer que nosso "gênero de nascimento" seria consequência de nosso sexo biológico, ou seja, nossa habilidade para 
reproduzir e características tais como "cromossomos sexuais, gônadas, hormônios sexuais e genitália interna e externa não ambígua" (DSM-V, 2014, p. 451).

A necessidade de se criar o termo e a noção de gênero surgiu, de acordo com - DSM-V (2014), quando os médicos começaram a se deparar com bebês que nasciam com "indicadores biológicos" diferentes, ou seja, com características de ambos os sexos, os intersexuais. Isso era considerado um problema, dado que não se poderia facilmente enquadrar o individuo nem na categoria mulher, nem na categoria homem, o que colocava a questão: como esse sujeito deveria agir, se vestir, se portar? Foi então que, segundo o DSM-V (2014), teve início a ideia de gênero - a princípio para resolver as questões dos intersexuais, mas, posteriormente, incorporado por outras pessoas, que afirmavam vivenciar um conflito entre a maneira como se identificavam e o seu sexo ou "gênero de nascimento". Dessa forma, o DSM-V (2014, p. 451) traz a seguinte definição da função do gênero: "denotar o papel público desempenhado (e em geral juridicamente reconhecido) como menino ou menina, homem ou mulher". O gênero poderia estar de acordo ou não com aquele que lhe foi designado no nascimento com base no seu sexo biológico, ou seja, nas características corpóreas dos sujeitos.

De qualquer modo, este manual psiquiátrico parte da ideia de que os "indicadores biológicos clássicos" responsáveis, de certa forma, pela designação de gênero, prediriam a maneira que um indivíduo deveria agir na sociedade, ou seja, o que é esperado e normal com base no seu órgão reprodutor. Logo, o DSM-V considera que usar vestido, gostar de brincar com bonecas - em especial a Barbie -, brincar de casinha e ter amigas garotas são coisas que seriam naturais e determinadas por uma vagina, ou seja, é um comportamento esperado somente de pessoas do sexo e gênero feminino. Assim como somente meninos podem apresentar interesse por esportes de contato, brincadeiras agressivas e competitivas e brincar com carrinho, porque isso seria consequência de se ter um pênis. Então, caso um menino tenha algum tipo de interesse em qualquer uma das coisas ditas anteriormente, associadas a se ter uma vagina e possuir os hormônios "femininos", ou, por outro lado, caso uma menina goste de brincar de esportes de contato, como por exemplo, o futebol, poderia já ser considerado uma das possiveis características diagnósticas (tópico esse do manual em que estão presentes essas descrições) da Disforia de Gênero, por serem entendidos como comportamentos atípicos ao gênero, ou seja, em desacordo com os comportamentos da maioria das outras garotas ou garotos em sua sociedade, aí entendidos como normais.

O DSM-V (2014, p. 451) oferece a seguinte definição para o vocábulo transgênero: "refere-se ao amplo espectro de indivíduos que, de forma transitória ou persistente, se identificam com um gênero diferente do de nascimento". $E$ ainda diferencia transgênero e transexual, afirmando que somente se enquadram neste último "problema clínico" quem deseja ou está passando por algum processo de transição social, podendo implicar ou não em mudanças 
corpóreas, que podem ser obtidas através do uso de hormônios e cirurgias. $\bigcirc$ que deixa claro novamente a dicotomia que o saber psiquiátrico estabelece entre sexo e gênero, presentes nesses dois termos.

Ao se analisar e comparar as versões IV e $V$ do DSM é possivel notar que algumas mudanças ocorreram, como, por exemplo, a admissão da existência de uma identificação do indivíduo com algo que não necessariamente seja homem ou mulher". Apesar desse assinalamento no trecho em que se é esclarecido o que se entende por "identidade de gênero", em praticamente todo o decorrer da categoria de Disforia de Gênero, as descrições e dados se dão baseados no binarismo homem e mulher, o qual há de se ver categoricamente no próprio tópico "características diagnósticas", quando os comportamentos são tomados a partir do referencial binário. Além disso, não se esclarece ou se aprofunda aquilo que se define como "uma categoria diferente de masculino ou feminino" (DSM-V, 2014, p. 451), pois a própria transexualidade continua a ser entendida com base no binarismo: o menino que se identifica como menina e a menina que se identifica como menino. Sendo assim, apesar de ser interessante o DSM-V começar já a considerar existências que vão para além de ser homem e/ou muIher, parece não ter sido suficiente a maneira com que o assunto foi abordado: de forma rápida, sem esclarecimentos, dando continuidade à lógica binária e patologizante ao longo do diagnóstico, presente na edição anterior.

Há que se considerar, entretanto, ao se comparar as duas últimas publicações do DSM, mudanças importantes em dois quesitos: na extensão e na quantidade de informações. O DSM-V detalha mais e esclarece sua visão sobre alguns pontos e termos, além de trazer mais dados estatísticos de estudos realizados recentemente, apesar de admitir que talvez os números não sejam fiéis à realidade, pois nem todos os transexuais procuram clínicas especializadas. Outra informação acrescentada foi a de que em culturas diferentes das quais vivemos também existem casos de "disfóricos de gênero", mesmo que não recebam esse nome diagnóstico, e o mesmo ocorre em lugares "com outras categorias de gênero ${ }^{12}$ institucionalizadas além de masculino ou feminino" (DSM-V, 2014, p. 458). Isso pode apontar para o fato de que talvez a transexualidade venha denunciar uma estrutura social e mostrar a existência de diferentes formas de viver que extrapolam o dito "normal", mesmo ocorrendo em outros lugares, onde mulher e homem possam receber nomes diferentes.

Prosseguindo o estudo comparativo, observa-se que o DSM-V, no tópico Fatores de Risco e Prognóstico, tentou encontrar motivos que pudessem justificar a transexualidade dos indivíduos, o que não foi feito na versão anterior. Para isso, foram considerados três âmbitos: temperamental; ambiental; genético/fisioló-

11 "Identidade de gênero é uma categoria de identidade social e refere-se à identificação de um indivíduo como homem, mulher ou, ocasionalmente, alguma categoria diferente de masculino ou feminino" (DSM-V, 2014, p. 451). 
gico. $O$ primeiro diz que os comportamentos atípicos de gênero do indivíduo podem acabar provocando a disforia. Esses comportamentos foram brevemente tratados anteriormente; aparecem exemplificados com a ocorrência de meninos brincando de Barbie ou meninas de cabelo curto, ou o chamado "cortes de cabelo de meninos" (DSM-V, 2014, p. 453) no manual. O segundo âmbito fala especificamente sobre os homens: quando estes têm irmãos mais velhos possuem maiores chances de serem disfóricos de gênero; somado a isso, "a transformação do travestismo fetichista habitual em autoginecofilia (i.e., excitação sexual associada ao pensamento ou à imagem de si mesmo como uma mulher)" (DSM-V, 2014, p. 457) poderia apontar também para a transexualidade. Por fim, no terceiro âmbito, os psiquiatras recorreram à genética e chegaram à conclusão de que em irmãos não gêmeos há fraca relação com a transexualidade, contudo, em irmãos gêmeos, em especial os monozigóticos, haveria certa correlação genética e o transtorno disfórico seria herdado. Sendo assim, a psiquiatria buscou justificativas no comportamento, no ambiente e na genética. Contudo, em todo momento isso parece convergir para o sujeito: mesmo no segundo âmbito, o ambiental, é falado sobre o travestismo do individuo que poderá se transformar em autoginecofilia. $O$ manual localiza o problema sempre no sujeito, mas não questiona em nenhum momento as normas de gênero que são tomadas como fixas e imutáveis e acabam por definir, junto com os atributos corporais, qual é o gênero do indivíduo.

Apesar dessas diferenças encontradas entre os DSM-IV e DSM-V é imperioso constatar que os conceitos mais se mantiveram do que foram mudados, a começar por pressupostos e ideias que partem de um dimorfismo tomado como natural e a-histórico, onde "as performances de gênero, a sexualidade e a subjetividade são níveis constitutivos da identidade do sujeito que se apresentam colados uns aos outros" (BENTO e PELÚCIO, 2012, p. 571). É cabivel ainda afirmar, baseado no estudo comparativo, que o masculino e o feminino são localizados também a partir de uma heterossexualidade compulsória, complementando um ao outro, e, sendo isso tomado como saudável e normal, caso haja qualquer fissura nessa linearidade se faz necessária uma intervenção feita por especialistas "para restabelecer a ordem e a 'coerência' entre corpo, gênero e sexualidade" (BENTO e PELÚCIO, 2012, p. 571). E é bem aqui que se localizam as questões de base para o diagnóstico do gênero.

Os critérios para se diagnosticar uma pessoa com Disforia de Gênero são praticamente os mesmos que eram utilizados para diagnosticar alguém com TIG. Continua a se considerar que a transexualidade seria definida pelo "forte desejo de pertencer ao outro gênero ou insistência de que um gênero é o outro" (DSM-V, 2014, p. 452), mesmo que o DSM-V já passe a apontar a possibilidade de um "gênero alternativo". Isso deve ser experienciado pelo indivíduo por no mínimo seis meses, de acordo com a versão atual (a anterior 
não estipulava tempo). Além disso, "está associada a sofrimento clinicamente significativo ou a prejuízo no funcionamento social, acadêmico ou em outras áreas importantes da vida do indivíduo" (DSM-V, 2014, p. 452). Esses dois pontos foram discutidos anteriormente à luz do olhar de Butler (2009), quando falado sobre o DSM-IV, apontando as problemáticas desse tipo de definição que se mantiveram ao longo desses anos.

A leitura e análise comparativa evidenciam também a manutenção da ideia de que há grandes chances dos transexuais experienciarem algum sofrimento e desconforto pelo fato de seus gêneros designado e expresso serem diferentes. Diante de tal evidência, é possível assumir então que o DSM parte da ideia de que existe um "Sentimento de adequação que as pessoas podem e devem ter, um sentimento de que este gênero é adequado para mim, adequado em mim. E que há um conforto que eu teria, poderia ter, e que poderia ser alcançado se eu me adequasse à norma" (BUTLER, 2009, p. 116).

Assim, a partir da noção de que as normas de gênero são fixas, a única solução seria o sujeito procurar se encaixar em alguma delas, ficando, dessa forma, confortável com seu gênero, mesmo que para isso precise transformar seu corpo. Além disso, as noções já brevemente expostas sobre as normas de gênero definidas pelos "indicadores biológicos clássicos" presentes no DSM-V se mantiveram iguais às que eram expostas na versão anterior do manual. E um ponto crítico dessa observação refere-se à problemática do não esclarecimento de onde vêm as descrições, que parecem se basear, segundo Butler (2009), em diversas observações que foram feitas acerca dos comportamentos - considerados atípicos - das crianças. Isso impele a pensar que uma pessoa viu uma criança agindo de tal forma e relatou, outras pessoas também viram e relataram, e da junção de todas essas observações e relatos foram feitas várias generalizações que os permitem classificar o que é normal e o que não é. Butler (2009, p. 117) coloca a questão: "Mas quem está observando e por meio de que grade de observação? Isso é o que não sabemos". E mais: podemos ainda - e devemos considerar a necessidade de questionar quais são os processos sócio-históricos que produziram esses próprios sujeitos que observaram.

Quanto aos meninos é discorrido, em ambas as versões do manual, ao seu eventual grande interesse em brincar com bonecas, em especial a Barbie, que seria um dos exemplos de "bonecas estereotípicas femininas" (DSM-V, 2014, p. 454). Mas Butler (2009) aponta que não nos é mostrado em nenhum momento como essas bonecas e brincadeiras funcionam no processo de formação da identidade de gênero das crianças. Parte-se da ideia de que, quando - menino brinca com a Barbie ou com qualquer outra boneca "de menina", ele deseja ser ela, sem considerar ao menos a possibilidade de ele querer "ser sua amiga, sua rival, sua amante" (BUTLER, 2009, p. 118). É possivel que ele tenha mais de um sentimento em relação a ela, ou que mude ao longo do 
tempo, em brincadeiras que se apresentam como exercícios constantes de improvisação envolvendo várias e complexas disposições. E a fala provocativa de Butler (2009, p. 118-119) é o alerta de que

Talvez se esteja brincando com a própria norma, quem sabe, explorando-a ou mesmo explodindo-a. Precisaríamos ver o ato de brincar como um fenômeno mais complexo do que como ele é considerado no DSM, se quisermos começar a colocar e a analisar questões desse tipo.

Em relação às meninas, igualmente permanece um ponto problemático: é posto que uma pessoa com Disforia de Gênero apresenta "forte desejo de pertencer ao outro gênero" (DSM- $V, 2014$, p. 452) sem que isso necessariamente seja dito pelo indivíduo, o que é claramente possivel concluir pelo uso do termo "ou" usado ao se referir à necessidade de ela insistir ou não no fato de que pertence a outro gênero. Logo, é pertinente levantar a questão já posta: como identificar o desejo de alguém sem que ele o verbalize? Parece que o manual dá uma solução a essa pergunta ao descrever os comportamentos que ajudam na formulação do diagnóstico. Sendo assim, com base nas observações de sujeitos - que não fica claro quem são - isso poderia ser feito. No parágrafo em que são postas as características diagnósticas das meninas é dito, entre outras coisas, que elas "preferem roupas e cortes de cabelo de meninos [...] [e] ter meninos como pares" (DSM-V, 2014, p. 453). E, logo em seguida, é dito que, frequentemente, pessoas estranhas percebem-nas como meninos. Como é possivel que um estranho identifique esse desejo de uma menina de ser do outro gênero e isso ser tomado como evidência? Butler (2009, p. 119) aponta que, ao que parece, esse tipo de designação de outro alguém, tem sido tomado como prova do desejo de pertencer ao outro gênero, como se fosse possivel um estranho saber sobre a constituição psicológica do sujeito em questão, ou como se ela lhe tivesse pedido alguma opinião ou parecer.

A continuidade do estudo comparativo entre o DSM-IV e DSM- $V$, confirma a percepção de que ambos localizam unicamente no indivíduo e na sua disforia a fonte do seu sofrimento, de sua ansiedade e de sua depressão, mas não se questionam se essas afecções podem ser decorrentes da falta de apoio a esses sujeitos, ou do fato do próprio diagnóstico, ou mesmo em consequência de uma sociedade que discrimina, ameaça e até mata com frequência os transexuais. $\bigcirc$ diagnóstico por si só funciona como uma pressão social "estabelecendo desejos como patológicos, reforçando a regulação e o controle daqueles que os expressam em ambientes institucionais" (BUTLER, 2009, p. 121) produzindo, consequentemente, sofrimento nessa população. Trata-se, portanto, de um mecanismo de poder que cria e reitera o papel social que foi estabelecido para os homens e as mulheres, as 
normas de gênero, e atua no sentido de adequar a todos nesta norma, patologizando os desviantes.

Para entender as consequências desse movimento de patologização na experiência concreta das pessoas trans seria possivel expor inúmeros exemplos. Contudo, para ilustrar o que aqui se estuda, trar-se-á à pauta algumas informações acerca da saúde pública dessa população no Brasil: em 2008 o Ministério da Saúde lançou a primeira Portaria instituindo o Processo Transexualizador no Sistema Único de Saúde (SUS). Nesta portaria, foi levada em consideração tanto a orientação sexual, quanto a identidade de gênero como fatores condicionantes à saúde dos sujeitos. E não somente por dizerem respeito a um modo de existir e suas práticas, mas inclusive pelo fato de que a população LGBT, em especial transexuais e travestis, por não estar em conformidade com as normas sociais de "normalidade", é alvo frequente de estigma, discriminação e exclusão social - ocorrência que ocasionaria a violação dos direitos humanos desses sujeitos, dentre eles "os direitos à saúde, à dignidade, à não discriminação, à autonomia e ao livre desenvolvimento da personalidade" (BRASIL, 2008a). O Ministério da Saúde, em seu texto, define a transexualidade como um "desejo de viver e ser aceito na condição de enquanto pessoa do sexo oposto, que em geral vem acompanhado de um mal-estar ou de sentimento de inadaptação por referência a seu próprio sexo anatômico" (BRASIL, 2008a). Todas essas questões precisariam ser trabalhadas e levadas em consideração durante o atendimento integral ofertado em todos os serviços de saúde do SUS. Nesta portaria também foi considerada e tomada como base a Resolução n ${ }^{0} 1.652 / 2002$ do Conselho Federal de Medicina (CFM), em vigor na época, que dizia respeito aos procedimentos de transgenitalização e que definia a transexualidade como um "desvio psicológico permanente de identidade sexual, com rejeição do fenótipo e tendência à automutilação e ou autoextermínio" (CFM, 2002).

No mesmo ano o Ministério da Saúde lançou outra Portaria, SAS/MS n ${ }^{\circ} 457$, ainda sobre o Processo Transexualizador no SUS. No âmbito dessa segunda portaria, entende-se explicitamente a transexualidade como um transtorno mental tal como previsto na Classificação Estatística Internacional de Doenças e Problemas Relacionados à Saúde (CID-10), e sendo assim, se faz necessário o diagnóstico de "transexualismo" para possibilitara o acesso às intervenções cirúrgicas, tal qual como previsto pelo CFM, estabelecendo também que as funções do psicólogo e do psiquiatra seriam de avaliação psicológica e de acompanhamento terapêutico (BRASIL, 2008b). Ou seja, percebe-se, a partir disso, que, na experiência dessas pessoas, ser doente é condição para acessar direitos humanos fundamentais, como ter acesso à saúde, pois o próprio Estado apresenta esses sujeitos como transtornados. A violência contra as pessoas trans é, então, institucionalizada. 


\section{Homossexualidade e Transexualidade}

Para se compreender o processo de entrada da transexualidade nos manuais psiquiátricos, se faz necessária a análise de algumas transformações que estavam acontecendo no período próximo à publicação do DSM-III. Em 1973, a APA decidiu retirar a categoria Homossexualismo do seu manual, deixando de considerar oficialmente a homossexualidade como um transtorno mental. Essa postura se tornou concreta "com o lançamento da terceira versão deste manual (DSM-III), em 1980, já sem esta categoria" (BENTO e PELÚCIO, 2012, p. 572). Somado a isso, podemos considerar também sua decisão de abolir, em 1987, a "homossexualidade ego-distônica", que, segundo Butler (2009, p. 99) seria um vestígio restante das definições antigas. Contudo, nos anos seguintes a esses acontecimentos nota-se um grande crescimento de novas e diferentes categorias psiquiátricas que permaneceram patologizando os comportamentos dos indivíduos segundo a lógica heteronormativa, ou seja, a partir de "normas sociais que impõem não necessariamente a heterossexualidade em si, mas seu modelo a outras relações, inclusive entre pessoas do mesmo sexo" (MISKOLCI, 2014, p. 14), apontando para a necessidade constante de uma relação linear entre sexo, gênero, desejo e práticas sexuais.

A leitura mais atenta e o observação mais rigorosa demonstram, nos dias atuais, o pensamento contínuo de patologização da sexualidade dos indivíduos, mudando apenas o foco e o nome: antes as doenças apareciam sob os títulos de "perversões sexuais" e de "homossexualismo"; agora, são denominadas, dentre outras, Disforia de Gênero ${ }^{13}$. Partindo do pressuposto oferecido pelos manuais e por conceitos de diversas áreas do saber, o gênero somente pode ser compreendido quando consideradas as diferenças e complementaridades entre os sexos, quando meninas estão ligadas ao feminino e meninos ligados ao masculino: a heterossexualidade está postulada como algo fundamental para a existência e o sentido dos gêneros. Butler (2009) afirma que a APA continuou diagnosticando a homossexualidade ao estabelecer a categoria de TIG, apesar de isso ser feito de maneira menos explícita. Então, a homossexualidade se transforma em um problema de identidade de gênero. E é importante enfatizar que essa análise de Butler (2009) é referente ao DSM-IV, contudo, parece se aplicar à versão atual do manual. Tal constatação permite, perfeitamente, considerar que o traço homofóbico da classificação da APA permanece até hoje nos diagnósticos indiretos de homossexualidade, os quais definem um sujeito que sofre de Disforia de Gênero.

Vem de Butler (2009) a citação de um curioso caso da Associação Nacional

Reconhece-se aqui a necessidade da distinção entre os sujeitos políticos que compõem as siglas LGBT. Apesar das fronteiras entre o que o se defende na esfera política como "gênero" (a forma como cada um se enxerga e se identifica) e "sexualidade" (por quem há desejo sexual) serem frequentemente borradas nas categorias psiquiátricas citadas, se apresentam como experiências distintas, apesar da possibilidade de se relacionarem. A transexualidade se refere ao gênero, à identidade do sujeito, enquanto que a homossexualidade diz de um desejo sexual. Para efeito do que estamos discutindo aqui ressaltamos que nossa abordagem crítica se refere à caracterização dada no contexto do DSM. 
de Pesquisa e Terapia da Homossexualidade (NARTH), nos Estados Unidos da América (EUA): a autora demonstra como esses grupos, partindo da classificação da APA, patologizam a experiência trans demonstrando haver ali experiências homossexuais em todos os casos, seja quando considerados a partir do sexo biológico, seja quando considerados a partir do gênero. Esses grupos compreendem a transexualidade como características de gênero ou orientação sexual que o sujeito expressa e que são, de certo modo, erradas, pois rompem com a linearidade socialmente estabelecida entre sexo, gênero e orientação sexual. A autora demonstra, ainda, como nessas interpretações é sempre a parte masculina de uma mulher que irá desejar outras mulheres, assim como é a parte feminina de um homem que irá desejar outros homens. Dessa forma, é enfático entender como a lógica heterossexual age até mesmo nas concepções feitas acerca da homossexualidade, o que pode ser definido como heteronormatividade, ou seja, parte-se, a todo o momento, do pressuposto que os opostos se atraem.

\footnotetext{
Pode-se assim, de fato, alegar que a homossexualidade poderia ser compreendida como uma inversão de gênero e que a parte "sexual" permaneceria heterossexual, embora invertida. Seria aparentemente raro, segundo essa conceitualização, que as características de menino levassem um menino a ter desejo por outros meninos e que características de menina levassem uma menina a ter desejo por outras meninas. (BUTLER, 2009, p. 99-100).
}

No entanto, deslocando o crivo, mantendo fixado o pressuposto da lógica da heteronormatividade, tende-se a considerar que esses casos, "aparentemente raros", seriam resultado da atração do "sexo biológico" pelo sexo oposto, - que se traduz em homossexualidade lida a partir da tendência do gênero. Butler (2009, p. 100) afirma, então: "visto isso, seria possivel argumentar, não sem ironia, que $100 \%$ das pessoas diagnosticadas com TIG seriam, ao final, homossexuais!", apontando como esses tipos de noções de homossexualidade e gênero são distorcidas e falíveis. Contudo, não é possivel predizer com base no sexo de uma pessoa qual será sua identidade de gênero e muito menos para onde irá se direcionar seu desejo sexual, posto não haver uma linearidade entre sexo, gênero, desejo e práticas sexuais, apesar desse tipo de saber tentar naturalizar e normalizar essas relações.

A questão da sexualidade, mais especificamente da homossexualidade, está presente nas categorias TIG e Disforia de Gênero das três últimas versões do DSM. A começar pelo DSM-III, quando "a desordem é subdividida de acordo com a história sexual prévia predominante" (DSM-III, 1980, p. 262), podendo ser heterossexual, homossexual, bissexual ou assexual, cabendo ao psiquiatra especificar, no código do diagnóstico, em qual das quatro categorias o sujeito transexual se enquadraria. No DSM-IV, no tópico "especificadores", aponta-se para 
a necessidade do psiquiatra especificar, no diagnóstico, se o indivíduo em questão sente "atração sexual pelo sexo masculino, atração sexual pelo sexo feminino, atração sexual por ambos os sexos e ausência de atração sexual por nenhum dos sexos" (DSM-IV, 2002, p. 549). Quanto aos homens, é possivel encontrar esses quatro especificadores. E sobre as mulheres com TIG, é dito que são raros os casos em que sentem atração sexual pelo sexo masculino. Continua-se a falar sobre o desejo sexual dos transexuais no tópico "curso", além de apontar a travestilidade como uma patologia. Aqui, fica clara a necessidade de identificar a bissexualidade, a homossexualidade e o desejo por nenhum sexo no diagnóstico de TIG, mas por quê? Procuram estabelecer, a todo momento, relações entre o gênero e a sexualidade dos sujeitos, o que acaba por dar continuidade à patologização, não apenas da transexualidade, mas também da homossexualidade e de qualquer outra modalidade de desejo que não seja heterossexual.

O DSM-V continua, assim, a tentativa da versão anterior do manual de associar a homossexualidade com a transexualidade. Este contém ainda mais informações acerca do assunto. Afirma-se que tanto homens quanto mulheres "ao nascimento", que "persistem" em sua Disforia de Gênero - segundo o manual nem todos serão disfóricos de gênero por toda a vida - sentem, na maioria dos casos, atração sexual por pessoas de mesmo sexo de nascimento. Antes de tudo, é importante sinalizar a postura que a APA assume frente aos transexuais: em momento algum, há aceitação e tratamento de referência ao indivíduo pelo gênero com o qual se identifica, ao contrário: todas as falas sobre essas pessoas ocorrem através da referência ao gênero que lhes foi atribuído ao nascimento (ou o sexo biológico), o qual seria, portanto, o considerado normal e correto. Posto isso, esse dado que o DSM-V traz de que grande parte dos "disfóricos" se interessa por pessoas do mesmo sexo - considerando o gênero designado - apontaria para uma suposta homossexualidade desses sujeitos. Contudo, esse tipo de entendimento parece distorcido, na medida em que o DSM, ao desconsiderar a identidade do sujeito, tratando-o por aquilo com que ele não se identifica, toma essa relação como uma mulher desejando outra mulher e um homem desejando outro homem, pois, segundo tal raciocínio, uma pessoa a quem foi atribuído o sexo feminino ao nascimento, seria sempre uma mulher, assim igualmente no caso dos homens. De acordo com essa lógica, independentemente de qualquer coisa, das transformações corporais e sociais pelas quais esses sujeitos possam passar, estes seriam eternamente tratados por aquilo que lhes disseram que eram quando nasceram. Descartada, então, a identidade que o sujeito assume não se considera se tratar de uma relação heterossexual, mesmo quando referentes a casos de um homem transexual desejando uma mulher ou uma muIher transexual desejando um homem. Portanto, fadado os transexuais a serem eternos homens e mulheres de "mentira", "farsantes", o DSM jamais poderia considerar essas relações como heterossexuais. Uma vez mais, o critério da he- 
terossexualidade compulsória (macho/fêmea) reproduz e multiplica binarismos (sexo/gênero; natureza/cultura; homem/mulher; cis/trans; homossexualidade/ heterossexualidade), sem nada explicar.

E quanto às crianças cuja Disforia de Gênero não persiste, também se confirmaria presente, na maioria dos casos, a homossexualidade:

\begin{abstract}
No caso de crianças do sexo masculino ao nascimento cuja disforia de gênero não persiste, a maioria é androfüica (sente atração física por homens) e frequentemente identifica a si mesmo como gay ou homossexual (variando de 63 a 100\%). No caso de crianças do sexo feminino ao nascimento cuja disforia de gênero não persiste, o percentual de ginecofüicas (sentem atração física por mulheres) e que identificam a si mesmas como lésbicas é menor (variando de 32 a 50\%). (DSM-V, 2014, p. 456).
\end{abstract}

Nesses casos, portanto, parece se tratar de fato da homossexualidade, pois a ocorrência é de pessoas cuja identidade de gênero é masculina, sentindo atração sexual por outros homens, e pessoas cuja identidade de gênero é feminina, sentindo atração sexual por outras mulheres. Portanto, de acordo com a perspectiva do DSM-V, a conclusão possivel é a de que a maioria dos sujeitos portadores de Disforia de Gênero em algum momento, seja ela persistente ou não, é homossexual. Logo, um diagnóstico de transexualidade teria como consequência, na maioria dos casos, um diagnóstico concomitante de homossexualidade. Essa associação segue no tópico em que se discorre sobre o desenvolvimento e curso da Disforia de Gênero. Ali também é dito que nos casos em que a disforia começa precocemente em pessoas do sexo masculino ("ao nascimento"), quase sempre há um desejo sexual por outros homens e mais: é possivel que em algum momento da vida a disforia desapareça e então essas pessoas comecem a se identificar "como gays ou homossexuais, ocorrendo, em seguida, a recorrência da disforia de gênero" (DSM-V, 2014, p. 456). Já nos casos em que a Disforia de Gênero começa tardiamente em pessoas do sexo masculino existe, com frequência, "comportamentos de travestismo" que provocam excitação sexual. Além disso, mulheres transexuais cuja disforia acontece tardiamente e que moram com mulheres, após fazerem a transição de gênero, acabariam por assumir também uma identidade lésbica. A homossexualidade nesse caso, que aparece no texto sob o termo "lésbica", é apresentada como algo com o qual o sujeito se identifica e não como a posição que o DSM-V toma frente a essa situação, ou seja, não é de fato considerada como relação lésbica pelo manual. Aponta-se também para a questão do "travestismo" que parece ser exposto como um problema. Por fim, no caso das mulheres ("ao nascimento") também se diferencia entre aquelas cuja disforia se iniciou precoce e tardiamente. No primeiro caso é dito que, quase sempre, 
sentem desejo sexual por outras mulheres. E na segunda situação sentiriam desejo sexual por homens e que, após transitarem de gênero assumiriam uma posição de homem gay. Em ambos a homossexualidade é apontada: primeiro, pelo próprio manual, pelo fato de suas "características biológicas clássicas" dizerem que são mulheres e em se interessando por mulheres, independentemente de sua identidade de gênero, seriam homossexuais. Já quanto às mulheres ("ao nascimento") que sentem atração por homens, após a transição se diriam gays. E, embora o manual assuma uma postura que lhe impede, no segundo caso, de entender essa relação como homossexual, aponta para a essa identidade sexual que o sujeito assume. Sendo assim, nas duas situações a homossexualidade é posta.

\section{Considerações finais}

Considerando todas as informações apresentadas, é possivel dizer que o DS$\mathrm{M}-\mathrm{V}$ continua atuando na direção de diagnosticar a homossexualidade, apesar de fazê-lo sob os moldes de um problema de Disforia de Gênero. A lógica homofóbica da APA permanece até os dias atuais, ainda que de maneira disfarçada. Corroboram com essa avaliação as questões elencadas por Butler (2009) ao falar sobre o DSM-IV, as quais parecem completamente aplicáveis também à versão atualizada do manual psiquiátrico, em vigência. Sendo assim, considera-se legítimo dizer que o DSM nunca deixou de considerar a homossexualidade como uma doença, ainda que modificada a maneira de apresentá-la: agora dentro de outras categorias diagnósticas, com informações aparentemente despretensiosas que parecem compor e caracterizar esse amplo espectro de pessoas e suas vivências, dentre elas, as pessoas trans, ou segundo o nome diagnóstico, os disfóricos de gênero. Verifica-se que o caráter homofóbico não se restringe aos termos usados para se referir a essas vivências. Ele atua, por outro lado, de maneira mais ampla ao postular a heterossexualidade compulsória em todas as vivências como única forma possivel e inteligivel de existência. Em sua finalização, este estudo não pode se furtar a considerar as diversas particularidades das vivências dos atores que hoje compõem a população LGBT em geral, seja no que tange ao lugar social que ocupa, seja no que concerne às suas lutas específicas. Ressalta-se, uma vez mais, reforçando afirmação anterior ${ }^{14}$, ser o foco do presente artigo analisar o lugar da homossexualidade nos documentos psiquiátricos, o que não desobriga da necessidade de considerar a diversidade com que os novos aparatos médicos/ psiquiátricos utilizados passam a agregar outros tipos de sujeitos, os quais, por sua vez, passam a ser alvo de tratamentos e discursos específicos. Tal entendimento aponta para a premência de, em análises futuras, discorrer sobre a especificidade do tratamento que vem sendo dado a essas experiências diversas. 


\section{Referências}

AMERICAN PSYCHIATRIC ASSOCIATION. DSM-III - Diagnostic and Statistical Manual of Mental Disorders. 3 ed. Washington, D.C: Copyright, 1980.

. DSM-IV-TR - Manual diagnóstico e estatístico de transtornos mentais. 4 ed. Porto Alegre: Artmed, 2002.

DSM-V - Manual diagnóstico e estatístico de transtornos mentais. 5 ed. Porto Alegre: Artmed, 2014.

ARÁN, Márcia. A Transexualidade e a Gramática Normativa do Sistema Sexo-Gênero. Ágora, Rio de Janeiro, v. 9, p. 49-63, jan/jun. 2006.

AYOUCH, Thamy. Da transsexualidade às transidentidades: psicanálise e gêneros plurais. Percurso, São Paulo, n. 54, p. 23-32, jun. 2015.

BENTO, Berenice; PELÚCIO, Larissa. Despatologização Do Gênero: A Politização Das Identidades Abjetas. Revista Estudos Feministas, Florianópolis, v. 20, p. 569-581, maio/ago. 2012.

BENTO, Berenice. O que pode uma Teoria? Estudos Transviados e a Despatologização das Identidades Trans. Revista Florestan, São Carlos, n. 2, p. 46-66, nov. 2014.

BRASIL. Portaria n ${ }^{0}$ 1.707, de 18 de agosto de 2008. Institui, no âmbito do Sistema Único de Saúde (SUS), o Processo Transexualizador, a ser implantado nas unidades federadas, respeitadas as competências das três esferas de gestão. Diário Oficial da União, Brasilia, DF, 2008a.

Portaria $n^{0} 457$, de 19 de agosto de 2008. Dispõe sobre o Processo Transexualizador no âmbito do Sistema Único de Saúde (SUS). Diário Oficial da União, Brasillia, DF, 2008b.

BUTLER, Judith. Desdiagnosticando o gênero. Physis Revista de Saúde Coletiva, Rio de Janeiro, v. 19, p. 95-126, 2009.

Problemas de Gênero: Feminismo e subversão da identidade. Rio de Janeiro: Civilização Brasileira, 2014.

CONSELHO FEDERAL DE MEDICINA. Resolução $n^{0}$ 1.652, de 6 de novembro de 2002. Dispõe sobre a cirurgia de transgenitalismo e revoga a Resolução CFM no 1.482/97. Diário Oficial da União, Brasilia, DF, n. 232, p. 80-81, 02 dez. 2002. Seção I. 
DUNKER, Christian Ingo Lenz; KYRILLOS NETO, Fuad. A psicopatologia no limiar entre psicanálise e a psiquiatria: estudo comparativo sobre o DSM. Vínculo, São Paulo, v. 8, n. 2, p. 1-15, dez. 2011.

FREIRE, L. A Máquina da Cidadania: uma etnografia sobre a requalificação civil de pessoas transexuais. 2015. Dissertação (Mestrado em Antropologia Social) Universidade Federal do Rio de Janeiro, Rio de Janeiro, 2015.

IOTTI, Paulo. Medieval, absurda e inconstitucional: sobre a decisão que permitiu a "cura gay". 2017. Disponivel em: <http://justificando.cartacapital.com. $\mathrm{br} / 2017 / 09 / 18 /$ medieval-absurda-e-inconstitucional-sobre-decisao-que-permitiu-cura-gay/>. Acesso em: 16 ago. 2018.

LAQUEUR, T. Inventando o sexo. Rio de Janeiro: Relume Dumará, 2001.

MICHAELIS. Dicionário Brasileiro da Língua Portuguesa. 2018. Disponível em: $<h t t p: / /$ michaelis.uol.com.br/busca? $r=0 \& f=0 \& t=0 \&$ palavra=disforia>. Acesso em: 16 ago. 2018.

MISKOLCl, Richard. Estranhando as Ciências Sociais: Notas Introdutórias Sobre Teoria Queer. Revista Florestan, São Carlos, n. 2, p. 08-25, nov. 2014.

SCOTT, Joan. Gênero: uma categoria útil de análise histórica. Educação e Realidade, Porto Alegre, v. 20, n. 2, p. 71-99, jul./dez. 1995.

Recebido em março de 2018.

Aprovado em setembro de 2018. 